\title{
Optic Neuropathy Mimicking Normal Tension Glaucoma Associated with Internal Carotid Artery Hypoplasia
}

\author{
Kyoko Shidara and Masato Wakakura \\ Inouye Eye Hospital/ Tokyo \\ Japan
}

\section{Introduction}

Most cases of ischemic optic neuropathy are of sudden onset without any prior indication of visual field loss. In contrast, a gradual loss of the visual field is observed in normal-tension glaucoma (NTG). We here present a case in which we initially diagnosed NTG but upon further examination it was evident that ICA hypoplasia was present.

Horowitz et el. previously reported an uncommon case of anterior ischemic optic neuropathy that was associated with hypoplasia of the interanal carotid aretry (ICA) (Horowitz et al., 2001) . Here, we report on a curious case in which clinical expression mimicked NTG, but upon further examination there was considered have been an ischemic event due to ICA hypoplasia that was responsible for the noted visual field change.

\section{Case report}

In 2006, a 41-year-old female visited an ophthalmologist for the purpose of purchasing contact lenses. During the contact lens examination the patient was found to have excavation of the right optic disc. In the past, she had not been aware of any visual dysfunction, including visual blurring, visual field loss or transient monocular blindness. After being diagnosed as having glaucoma treatment was immediately begun. However, the ophthalmologist in charge of the treatment considered her visual field to be atypical and that her disc morphology was not compatible with the observed field defect as is the case in glaucoma.

Therefore, in February of 2007, 1 year after her original examination, she was referred to our hospital. Upon initial presentation at our clinic, her visual acuity (VA) was 20/20 OU. She had a right relative afferent pupillary defect (RAPD) and her intraocular pressures (IOP) were $12 \mathrm{mmHg}$ OD and $10 \mathrm{mmHg}$ OS. Biomicroscopic examination showed normal findings in both eyes. Fundoscopy revealed large disc excavation in her right eye with an almost normal left eye, and there was chorioretinal atrophy in both eyes (Fig. 1). Goldmann perimetry indicated there was a multidirectional, irregular defect at the temporal and nasal quadrants of her right eye (Fig. 2). 
Irregular depression at nasal and inferior quadrant of right eye and normal field of left eye on Goldman perimetry.

Over a 3.5-year period, there was no further significant progress noted for this multidirectional and irregular visual field defect. Fluorescein angiography (FA) showed neither leakage nor hyperfluorescence. The retinal nerve fiber layer thickness, as measured by optic coherence tomography (OCT), showed diffuse thinning in her right eye. Borderline results were found for the Moorfields Classification, which used the Heidelberg retina tomography (HRT).

Since she had a RAPD and her visual field and optic disc findings were not typical of glaucoma, we performed magnetic resonance imaging (MRI) and magnetic resonance angiography (MRA) of her head. MRA revealed there was approximately a $50 \%$ stenosis of the ophthalmic portion of the right internal carotid artery (ICA) (Fig. 3).

MRA showing approximately $50 \%$ stenosis of the right ICA of ophthalmic portion and slight narrowing of the right anterior cerebral artery on brain MRA.

However, there were no abnormality of the right anterior cerebral artery. Three-dimensional computed tomography (3D-CT) indicated that there was a partial stenosis of the right cervical ICA, which was strongly suggestive of hypoplasia (Fig. 4).

A part of hypoplasia and stenosis of the right cervical ICA on 3D-CT.

Color Doppler imaging (CDI) was performed in order to determine the functional characteristics of the internal carotid artery stenosis. As shown in Figure 5, CDI showed a downstream reversed diastolic flow in the right ophthalmic artery. In normal waveforms, there is an initial sharp rise with a small notch noted on the down slope of the peak.

(A)

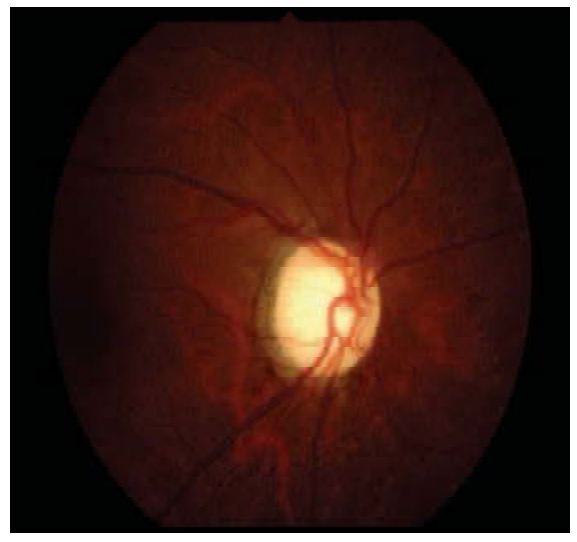

(B)

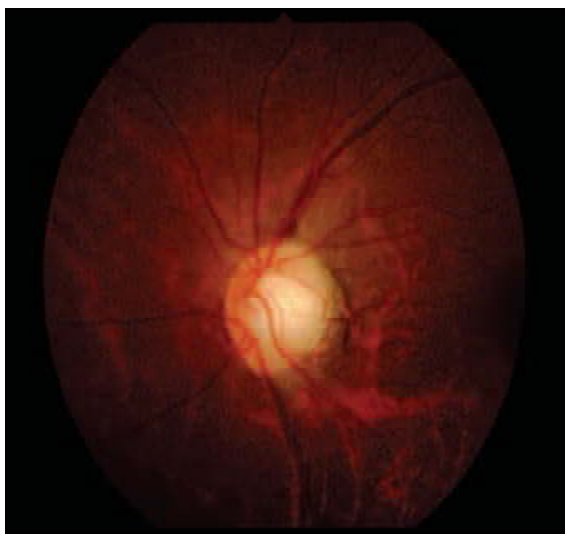

Fig. 1. Fundes photograph

A: right eye B: left eye. Note large cupping in the right eye and almost normal in the left eye. 

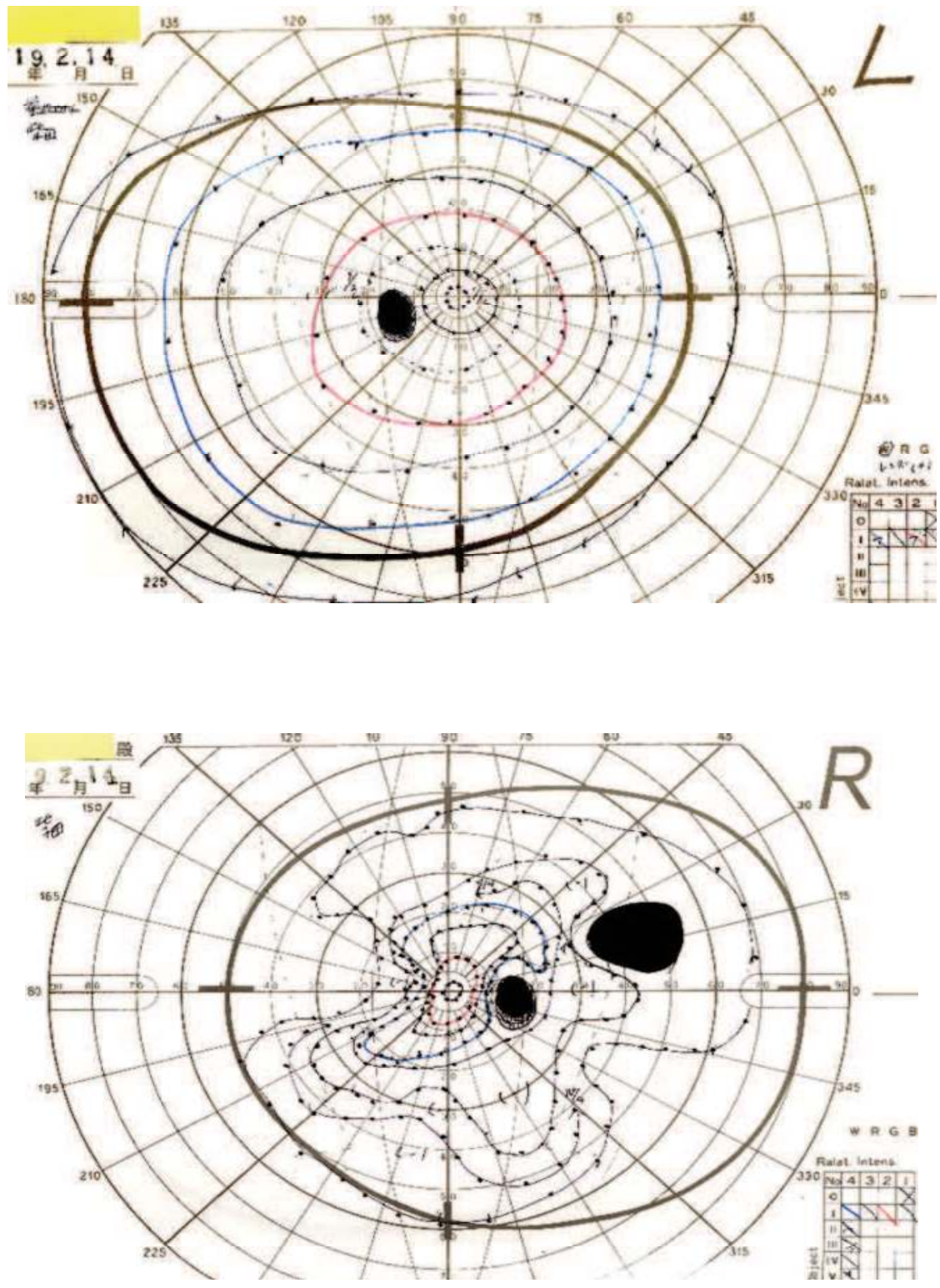

Fig. 2. Goldman perimetry. 


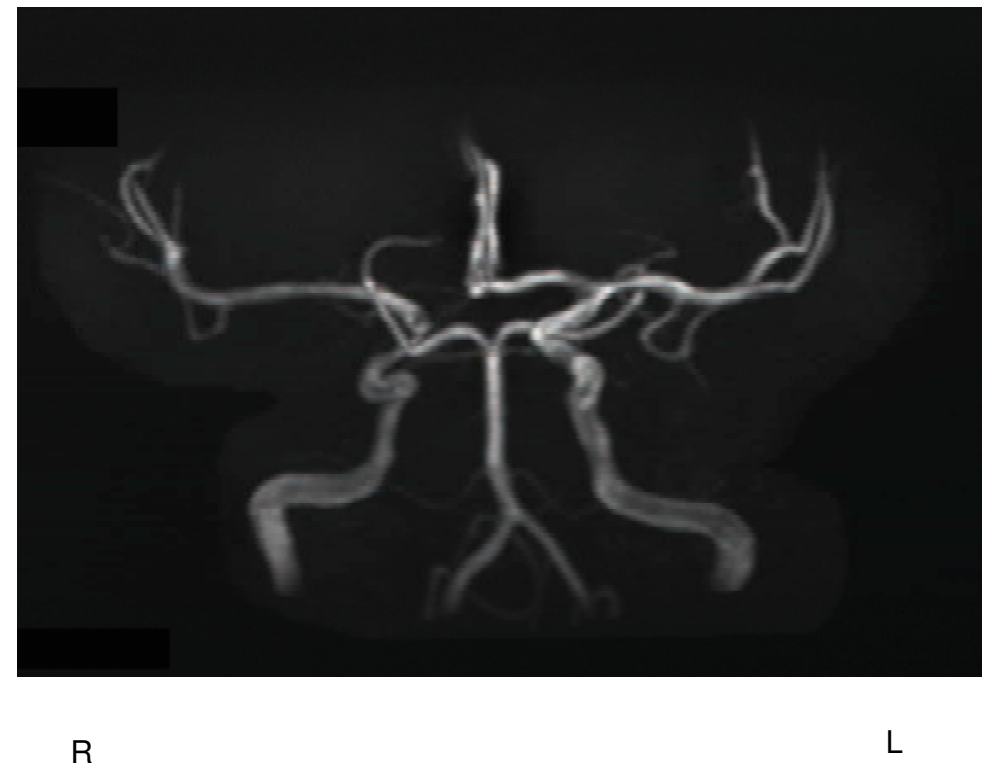

Fig. 3. MRA

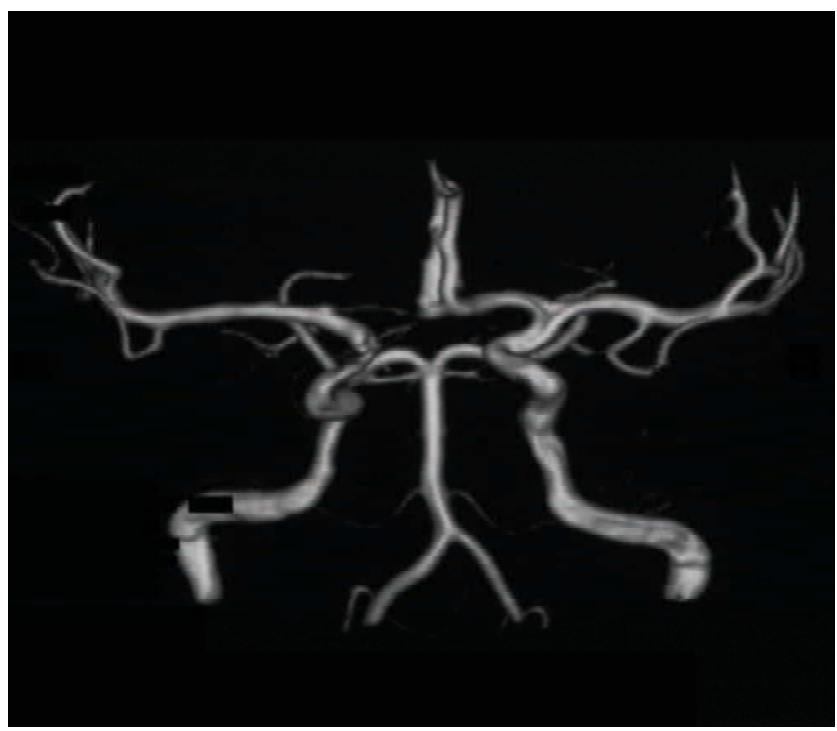

R

L

Fig. 4. 3D-CT 


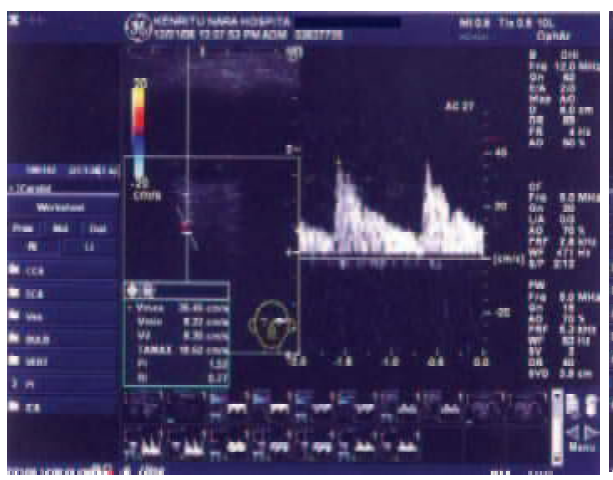

Left eye

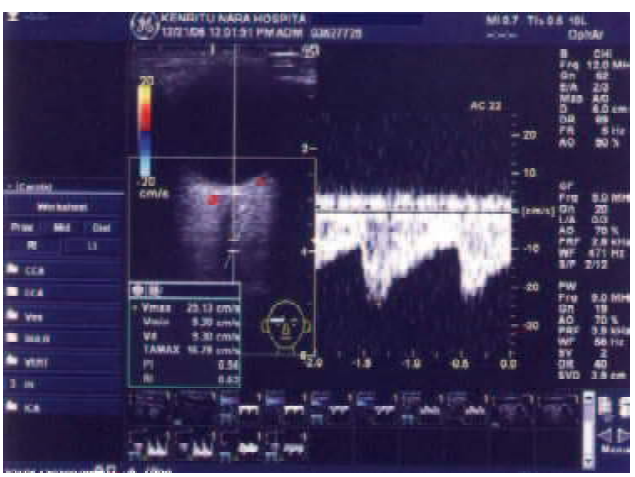

Right eye

Fig. 5. Orbital CDI.

Note downstream of the right ophthalmic artery and normal upstream of the left ophthalmic artery on orbital CDI.

In the current case, there was an atypical pattern with a slow rising wave that lacked the notch found in the normal waveform. There was a normal typical flow in the left ophthalmic artery. These findings indicated that there was regurgitation of the right ophthalmic artery. This can be explained by a significant stenosis of the right ICA leading to a reverse flow in the right ophthalmic artery (Fujioka $S$ et al., 2003).

To assess the optic disc change, we repeatedly conducted HRT during the year that followed. No significant changes were observed.

We also examined the patient using a Humphrey Field Analyzer (program 30-2 SITA standard test). The patient is currently being seen every 3 months. At the present time, she has completed 3.5 years of follow-up and there has been neither progression of the visual field defect nor any change in the disc appearance (Fig. 6).

\section{Discussion}

It has been previously reported that ocular ischemic phenomena can result from disease of the cervical ICA: for example amaurosis fugax (AF), acute retinal artery obstruction, branch retinal artery obstruction (BRAO), ischemic optic neuropathy and the ocular ischemic syndrome where the entire globe shows evidence of poor perfusion. There are also case reports of normal tension glaucoma associated with chronic reduction of retrobulbar blood flow(Costa VP et al.,1998).

In the current case, the initial diagnosis was thought to be NTG, however the atypical disc and visual field defects were against this diagnosis. MRA and 3-D CT examinations suggested that there was hypoplasia of the right cervical ICA and orbital CDI of the right ophthalmic artery indicated reversed diastolic. These results suggested that the presumed ischemic optic neuropathy was associated with stenosis and hypoplasia of the right cervical ICA( Kawaguchi S et al., 1999).

Although the finding in the carotid artery could be incidental and unrelated to the optic cupping in this case, in our opinion the carotid artery abnormalities could have been 


\section{Humphrey Field Analyzer (30-2 SITA-Standard)}

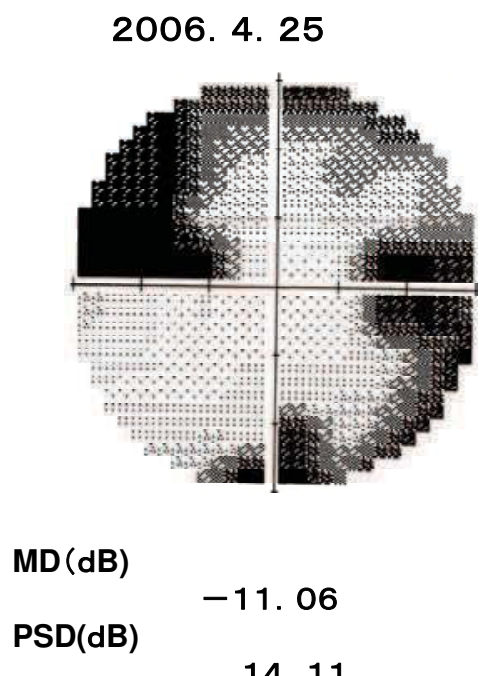

14. 11

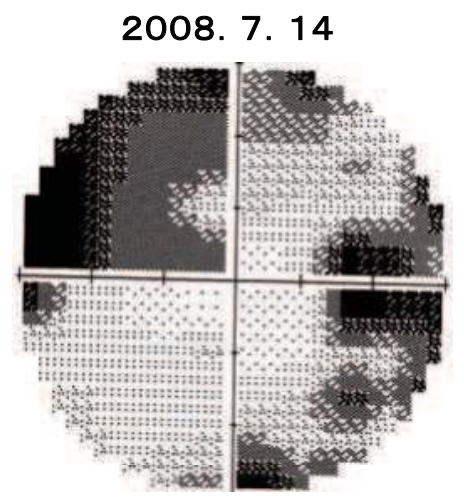

$-9.19$

10. 37

Fig. 6. Humphrey Field Analyzer (30-2 SITA standard test).

Humphrey Field Analyzer (30-2 SITA standard test) initially show decreased sensitivity at each quadrant and MD and PSD revealed no significant changes during 3.5 year.

associated with ischemia of the nerve head at some time. There may be several other possibilities that could explain the ischemic ocular neuropathy including, the accumulation of subclinical ischemic events on the optic nerve, which is referred to as chronic progressive ischemic optic neuropathy (Knox DL et al.,1971), hypoperfusion of the ophthalmic artery (Burghaus L et al.,2007), ischemic optic neuropathy in childhood(Chutorian AM et al,2002), and conventional anterior or posterior ischemic optic neuropathy that was not noticed by the patient.

Of these optic neuropathy-related ischemic events, only anterior optic neuropathy has been reported to be associated with ICA hypoplasia. It is common knowledge that there is a sudden onset for ischemic events. In the present case, however, for at least 3.5 years there has been neither significant progression of the disc morphology nor any visual field defect. Within this context, there are two possibilities that might explain our observations. One is that there is a very slow progressive ischemic syndrome that is present. This type of ischemic optic neuropathy has been reported as chronic progressive ischemic optic neuropathy, although at the current time there is still much dispute with regard to this entity (Lessell S et al., 1999).

Another possibility is that this type of ischemic optic neuropathy occurs during infancy. Since the patient did not have any subjective symptoms and the current clinical stage of the 
optic neuropathy appears to be non-active, it very well could be that the patient may simply have had no previous awareness of the initial ischemic event.

Thus, based upon the ICA congenital anomaly, we speculate that the ischemic optic neuropathy could even have occurred during infancy. An ischemic event of this type in the optic nerve could result in a slight enlargement of cupping (Saito $\mathrm{H}$ et al., 2008), as well as a non-progressive change in the visual field.

In the ocular ischemic syndrome there are reports that the flow dynamics of the ophthalmic artery can spontaneously improve (Ward JB et al., 1995). In the current case, CDI documented that the right ophthalmic artery exhibited a reversed flow, indicating that there was the normal flow, indicating that there was the normal collateral pathway from the external carotid artery to the right ophthalmic artery. It is our belief that this collateral pathway provided indispensable circulation.

Hypoplasia of the ICA is rare : less than 100 cases having been reported (Horowitz et al., 2001). Although this condition rarely occurs, the possibility that hypoplasia of the ICA could be the associated with an ischemic ocular syndrome that mimics NTG needs to be taken into consideration when diagnosing such patients.

There is no report of the same or a similar case like our report in the literature, but the neurovascular contact of ICA or the anterior cerebral artery has been described in the literature. Compression of the optic nerve by a fusiform enlagement of the internal carotid artery is originally described in Japanese (Miyake $Y$ et al.,1978).

Subsequently, Uchino et al reported a 71-yaer old woman who had a unilateral visual field defect due to optic nerve compression by sclerotic internal carotid artery. This case underwent decompression surgery and then, the visual field was improved(.Uchino $M$ et al.,1999). According to a retrospective neuroimaging study for reasons unrelated to loss of vision, optic neuropathy, or carotid artery disorders, the frequency of the artery relationship included contact one or both optic nerves in $70(70 \%)$ of 100 patients. The anatomic compression of the optic nerve depended upon the diameter of the carotid artery (Jacobson DM., 1997).

Although uncommon, intracranial compression of the optic nerve by the carotid artery should be always considered when seeing unknown optic neuropathy(Jacobson DM.,1999).

Compression of the optic nerve seems to also occure by megadolichoectatic ophthalmic artery (Gire J.,2010).

The compression may be induced not by anterior cerebral artery (Nishioka T.,1995), but they also suggested the progressive optic neuropathie $\mathrm{s}$ due to compression by the plolapsing gyrus rectus (Nishioka T.,2004).

Longstanding compression of the intracranial optic nerve may produce a nerve fiber bundle pattern of visual field loss and excavation of the optic disc, two signs consistent with glaucoma. However most patients with these two signs had other features atypical of glaucoma, including pallor of the neuroretinal rim and impairment of visual acuity and color vision. The presence of such signs should alert one the possibility that a patient with visual field loss and excavation of the optic disc may be harboring a compression lesion, not suffering from glaucoma(Jacobson DM.,1999).

It is necessary to assess a condition of intracranial using thin-slice MRI or angiography, whenever the patients has a optic neuropathy of an unknown etiology or the case having a visual field changes like a glaucoma, but does not agree with clinical findings. 


\section{References}

Burghaus L et al(2007).. Acute loss of vision with hypoplasia of the contralateral carotid artery. J Stroke Cerebrovasc Dis ,2007,16,43-44.

Chutorian AM et al(2002).Anterior ischemic optic neuropathy in children. Pediatr Neurol ,2002,26,358-364.

Costa VP et el.(1998) Collateral blood supply through the ophthalmic artery. A steal phenomenon analyzed by color Doppler imaging. Ophthalmology, 1998,105,689-693.

Fujioka S.(2003). Use of orbital color Doppler imaging for detecting internal carotid artery stenosis in patients with amaurosis fugax. Jpn J Ophthalmol ,2003,47,276-280.

Gire J et al(2010). Optic Nerve Compression by an Intraorbitctatic Megadolichoectatic Ophtalmic Artery. Orbit. 2010,29,60-62.

Horowitz J et al.( 2001). Internal carotid artery hypoplasia presenting as anterior ischemic optic neuropathy. Am J Ophthalmol, 2001,131,673-674.

Jacobson DM et al,(1997). Optic nerve contact and compression by the carotid artery in asymptomatic patients. AJO ,1997,123,677-683.

Jacobson DM.(1999).Symptomatic compression of the optic nerve by the carotid artery. Ophthalmology.1999, 106,1994-2004.

Kawaguchi S et al,(1999). Effects of bypass on ocular ischemic syndrome caused by reversed flow in the ophthalmic artery. The Lancet, 1999,354,2052-2053.

Knox DL et al,(1971).Slowly progressive ischemic optic neuropathy. A clinicopathologic case report. Trans Am Acad Ophthalmol Otolaryngol 1971,75,1065-1068.

Lessell S.(1999). Nonarteritic anterior ischemic optic neuropathy. Arch Ophthalmol 1999,117,386-388.

Miyake $\mathrm{Y}$ et al,(1978).A case of compression of the optic nerve by a fusiform enlargement of the internal carotid artery. Rinsho Shinkeiganka. ,1978,18,608-613.

Nishioka T et al(1995).Progressive blurring of vision in both eyes. The Lancet.1995,346,1402.

Nishioka T et al,(2000). Plolapsing gyrus rectus as a cause of progressive optic neuropathy. Neoro Med Chir. 2000,40,301-309.

Saito $\mathrm{H}$ et al,(2008).Optic disc and peripapillary morphology in unilateral nonarteritic anterior ischemic optic neuropathy and age- and refraction- matched normals. Ophthalmology, 2008, 115,1585-1590.

Uchino $\mathrm{M}$ et al,(1999). Unilateral visual field defect due to optic nerve compression by sclerotic internal carotid artery.Nouge,1999, 27,189-194.

Ward JB et al,(1995).. Reversible abnormalities in the ophthalmic arteries detected by color Doppler imaging. Ophthalmology 1995,102,1606-1610. 


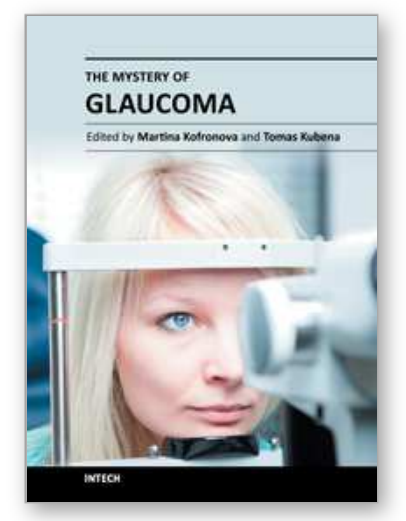

\author{
The Mystery of Glaucoma \\ Edited by Dr. Tomas Kubena
}

ISBN 978-953-307-567-9

Hard cover, 352 pages

Publisher InTech

Published online 06, September, 2011

Published in print edition September, 2011

Since long ago scientists have been trying hard to show up the core of glaucoma. To its understanding we needed to penetrate gradually to its molecular level. The newest pieces of knowledge about the molecular biology of glaucoma are presented in the first section. The second section deals with the clinical problems of glaucoma. Ophthalmologists and other medical staff may find here more important understandings for doing their work. What would our investigation be for, if not owing to the people's benefit? The third section is full of new perspectives on glaucoma. After all, everybody believes and relies - more or less - on bits of hopes of a better future. Just let us engage in the mystery of glaucoma, to learn how to cure it even to prevent suffering from it. Each information in this book is an item of great importance as a precious stone behind which genuine, through and honest piece of work should be observed.

\title{
How to reference
}

In order to correctly reference this scholarly work, feel free to copy and paste the following:

Kyoko Shidara and Masato Wakakura (2011). Optic Neuropathy Mimicking Normal Tension Glaucoma Associated with Internal Carotid Artery Hypoplasia, The Mystery of Glaucoma, Dr. Tomas Kubena (Ed.), ISBN: 978-953-307-567-9, InTech, Available from: http://www.intechopen.com/books/the-mystery-of-glaucoma/opticneuropathy-mimicking-normal-tension-glaucoma-associated-with-internal-carotid-artery-hypoplasi

\section{INTECH}

open science | open minds

\author{
InTech Europe \\ University Campus STeP Ri \\ Slavka Krautzeka 83/A \\ 51000 Rijeka, Croatia \\ Phone: +385 (51) 770447 \\ Fax: +385 (51) 686166 \\ www.intechopen.com
}

\author{
InTech China \\ Unit 405, Office Block, Hotel Equatorial Shanghai \\ No.65, Yan An Road (West), Shanghai, 200040, China \\ 中国上海市延安西路65号上海国际贵都大饭店办公楼405单元 \\ Phone: +86-21-62489820 \\ Fax: +86-21-62489821
}


(C) 2011 The Author(s). Licensee IntechOpen. This chapter is distributed under the terms of the Creative Commons Attribution-NonCommercialShareAlike-3.0 License, which permits use, distribution and reproduction for non-commercial purposes, provided the original is properly cited and derivative works building on this content are distributed under the same license. 